\title{
Rabaska
}

Revue d'ethnologie de l'Amérique française

GIRARD, DENISE. Mariage et classes sociales. Sainte-Foy, Les

Éditions de l'IQRC/Les Presses de l'Université Laval, "Culture et société " 2002, 203 p. ISBN 2-89224-298-3

\section{Mandoline Langlois}

Numéro 1, 2003

URI : https://id.erudit.org/iderudit/201623ar

DOI : https://doi.org/10.7202/201623ar

Aller au sommaire du numéro

Éditeur(s)

Société québécoise d'ethnologie

ISSN

1703-7433 (imprimé)

1916-7350 (numérique)

Découvrir la revue

Citer ce compte rendu

Langlois, M. (2003). Compte rendu de [GIRARD, DENISE. Mariage et classes sociales. Sainte-Foy, Les Éditions de l'IQRC/Les Presses de l'Université Laval, « Culture et société » 2002, 203 p. ISBN 2-89224-298-3]. Rabaska, (1), 181-183.

https://doi.org/10.7202/201623ar d'utilisation que vous pouvez consulter en ligne.

https://apropos.erudit.org/fr/usagers/politique-dutilisation/ 
GIRARD, Denise. Mariage et classes sociales. Sainte-Foy, Les Éditions de l'IQRC/Les Presses de l'Université Laval, "Culture et société " 2002, 203 p. ISBN 2-89224-298-3.

Cet ouvrage s'adresse autant à un public général qu'à un public spécialiste intéressé par l'ethnologie et l'histoire. Publié dans la collection « Culture et société », il compare les rituels du mariage dans les classes sociales du milieu urbain de la société québécoise dans la première partie du XX $\mathrm{X}^{\mathrm{e}}$ siècle. Denise Girard a d'abord présenté cette étude comme thèse de doctorat en ethnologie à l'université Laval en 1998. L'auteur a réalisé ses recherches dans le cadre des travaux de l'Institut interuniversitaire de recherche sur les populations (IREP), situé à Chicoutimi.

L'objectif de cet ouvrage est de dégager les différences et les similitudes entre la classe bourgeoise, la classe moyenne et la classe ouvrière en prenant comme point de référence les rituels de mariage des Montréalais francophones entre 1925 et 1940. C'est en dressant un portrait approfondi et complet de ces rituels que l'auteur atteint ce vaste objectif. Girard pose l'hypothèse que la diversité des mariages urbains laisse entrevoir une hétérogénéité calquée sur l'organisation sociale. Pour elle, "l'existence même d'un rite ou la forme qu'il adopte se différencie souvent selon le milieu social où il a cours » (p. 16). L'approche comparative permet à l'auteur de montrer que le rite du mariage varie en fonction de la classe sociale. Sa recherche s'appuie sur 36 entrevues réalisées auprès de personnes d'origine canadienne-française qui sont nées à Montréal et qui se sont mariées dans cette même ville entre 1925 et 1940. 
L'ouvrage est divisé en deux parties. La première comprend trois chapitres qui portent respectivement sur « Le temps des amours », « La célébration du mariage » et « Les premiers pas de la vie à deux ». Ces chapitres sont d'abord constitués d'une section descriptive dans laquelle Denise Girard expose trois parcours parallèles qui décrivent les différents rituels liés au mariage en fonction des trois classes ci-haut énumérées. Cela permet la décomposition de rites en éléments significatifs. Chacun de ces chapitres se conclut par une section intitulée « Différenciation sociale » qui reprend la synthèse des données entre les classes étudiées. Par l'analyse comparative, l'auteur peut examiner les rapports entre la structure sociale elle-même et les modèles culturels. La deuxième partie de l'ouvrage, intitulée « Jeux d'interaction », ne comporte qu'un seul chapitre. Y est analysée la structure des rituels eux-mêmes afin de comprendre leur fonction sociale. Cette analyse transversale compare divers paramètres des rituels comme les rapports entre les groupes d'âge, entre les genres ou entre l'espace privé et public.

Les trois premiers chapitres suivent le déroulement chronologique du rite du mariage. Par exemple, le premier chapitre est divisé selon trois moments : tout d'abord la rencontre initiale, ensuite les fréquentations et, finalement, les fiançailles. Dans les familles bourgeoises, une étape est ajoutée avant la rencontre initiale, soit celle de "faire ses débuts ", qui consiste, pour les jeunes filles, à faire leur entrée dans le monde adulte. Le deuxième chapitre traite aussi de trois aspects : la préparation du mariage, la cérémonie religieuse et la noce. Il faut souligner que ces étapes sont ordinairement l'affaire de la fiancée et de sa famille, puisque c'est celle-ci qui débourse pour la célébration. Enfin, le troisième chapitre traite du voyage et de la nuit de noces et de l'installation du couple au foyer. L'auteur dégage un profil général de ces trois moments. Dans le quatrième chapitre, Denise Girard fait la synthèse des éléments du rituel du mariage et dégage la structure du rite de passage. Tout d'abord, elle remarque que les règles sont relativement homogènes au sein de la bourgeoisie, mais qu'elles varient à un plus grand degré au sein des autres classes. Ensuite, elle examine les rapports entre l'individu et sa famille et montre qu'ils sont relativement semblables d'une classe à l'autre, mais que c'est dans la classe moyenne que l'individu prend le plus d'initiatives. Un autre aspect traité est la différence entre l'espace privé et l'espace public. Pour l'auteur, ces deux espaces représentent bien la complexité de la stratification sociale des rituels puisque chaque séquence possède un aspect privé qui appelle une contrepartie publique. Enfin, elle dégage quatre valeurs dont l'importance varie en fonction des classes : la hiérarchie familiale placée sous l'autorité du père, l'organisation familiale 
où le mari est pourvoyeur et la femme, gardienne du foyer, l'amour et la virginité prénuptiale.

Denise Girard a dressé un bilan précis et complet du mariage et des classes sociales chez les Canadiens français de Montréal entre 1925 et 1940. Le plus grand mérite de cet ouvrage descriptif est de porter sur la réalité urbaine du mariage, notamment en milieu métropolitain, jusqu'ici peu explorée. Il faut certes souligner la rigueur de la démonstration et l'analyse minutieuse des données. Cette étude ethnohistorique s'appuie sur un corpus de données de terrain considérables qui pourront être utilisées par d'autres chercheurs et dans une perspective interdisciplinaire. Très à propos, tableaux et photographies agrémentent la lecture qui paraît parfois répétitive à cause du caractère comparatif de l'étude. Les extraits d'entrevues apportent d'ailleurs une couleur attrayante au texte et cassent la monotonie inhérente à la description. Bref, il s'agit d'un ouvrage de référence important sur le mariage dont l'apport principal est sans doute de renouveler les connaissances sur ce rite de passage pour la période étudiée, même si cette période est relativement courte.

Mandoline Langlois

Université Laval 